\title{
Influence of Paternalistic Leadership on the Staff's Performance
}

\author{
Yang Jing, Deng ZhiHua* \\ School of Business Administration, Guizhou University of Finance and Economics, Guiyang, Guizhou
}

Keywords: Paternalistic Leadership, Job Satisfaction, Organizational Citizenship Behavior, Workplace Deviance.

\begin{abstract}
Paternalistic leadership is originated from Chinese traditional culture and thus may be suitable in the context of Chinese enterprises. Based on the analysis of the data collected from 321 employees using SPSS and LISREL software, the study has found that paternalistic leadership styles have significant and positive impact on employee's job satisfaction and organizational citizenship behaviors, as well as negative impact on employee's workplace deviance. The results indicate that paternalistic leadership seems to be effective to increase employee's job satisfaction and OCB and reduce their workplace deviance in the enterprises in Mainland China.
\end{abstract}

\section{Introduction}

Due to the take-off and rapid growth of Chinese economy, many researchers are paying more attention to cultural factors in Chinese firms to explore the roots of success. Thus an indigenous theory of paternalistic leadership (PL) and a ternary model has been developed by Cheng, Chou, \& Farh (2000) [1], Paternalistic leadership is defined as a "style that combines strong discipline and authority with fatherly benevolence and moral integrity” Based on this definition, PL consists of three important elements: authoritarianism, benevolence, and moral leadership. Authoritarianism refers to a leader's behavior that asserts absolute authority and control over subordinates and demands unquestionable obedience from subordinates. Benevolence means that the leader's behavior demonstrates individualized, holistic concern for subordinates' personal or familial well-being. Moral leadership can be broadly depicted as a leader's behavior that demonstrates superior personal virtues, self-discipline, and unselfishness.

\section{Influence of Paternalistic Leadership on the Staff's Performance}

\subsection{The basic characteristics of paternalistic leadership}

The ternary model of paternalistic leadership developed by Cheng, Chou, \& Farh (2000) is generally accepted [1]. Paternalistic leadership is a "style that combines strong discipline and authority with fatherly benevolence and moral integrity". Paternalistic leadership includes three dimensions: benevolence, moral and authority. Benevolence leadership provides subordinates with individualized care. Moral leadership requires the leader should show a high degree of personal conduct and self-cultivation. Authority leadership emphasizes the leader's authority cannot afford to challenge, and requires employees should obey absolutely. Cheng (2000) [1] pointed out that paternalistic leadership is rooted in the traditional concept of leadership in Chinese culture, but also reflects on the nature of the characteristics of modern organization.

\subsection{Paternalistic leadership and job satisfaction}

In contrast, there are negative interactions of benevolence and authority, moral and authority on performance of employees (Cheng et al, 2003) [2]. Besides, there are some conflicts of three dimension of paternalistic leadership. It is difficult to make sure to the relationship between paternalistic leadership and work satisfaction. A study from Cheng (2003) [2] shows that benevolence and moral dimension are positively corrected to job satisfaction, while authority 
dimension is negatively correlated to job satisfaction. Culture will mediate the relationship between paternalistic leadership and job satisfaction. Cheng (2000) [1] show that traditional culture positively mediates authority dimension and attitude of employees. Although the paternalistic leadership is able to explain some variables in the Chinese organizations, the conclusions of the effects of paternalistic leadership are inconsistent contrasted with other leadership styles. Cheng (2003) [2] point out after controlling for transformational leadership, paternalistic leadership has significant impact on work satisfaction of subordinates. Although paternalistic leadership is constructed based on the local culture, effect of paternalistic leadership may not be the best. So, the authorpropose the hypothesis 1 (H1): compared to paternalistic leadership, increases job satisfaction of employees effectively.

\subsection{Paternalistic leadership and OCB}

A study from Cheng (2003) [2] finds that benevolence and moral leadership are positively corrected to extra behavior of employees, while authority is negatively corrected to it. Cheng (2004) [3] further point out that paternalistic leadership has a significant impact on OCB. The main effects of benevolence and moral are significant, while the main effect of authority is insignificant. It is difficult that paternalistic leadership provides subordinates with the equal individualized care. A high degree of benevolence and authority is difficult to coexist in a leader. Because of different treating toward subordinates and the conflicts of three dimensions, it is difficult to analyze the impact of paternalistic leadership. So, the author propose the hypothesis 2(H2): compared to paternalistic leadership, enhances OCB of employees effectively.

\subsection{Paternalistic leadership and deviant behavior}

Farh (2000) [4] show that authority dimension leads to resentment and resistance of employees, in particularly the young and high-knowledge members. Benevolence and moral are regarded as condescending graces to subordinates, which easily lead to unfair feeling of employees. Hepworth (2004) [5] point out that too much control and command to employer will result in the sense of injustices of employees which easily lead to deviant behavior. Tepper (2001) [6] points out concealing information, indifferent treatment, humiliating or mocking subordinates lead to deviant behavior of employees. Therefore, the behavioral characteristics such as strict control, ignoring recommendations and depreciating contribution easily lead to deviant behavior. So, the author propose the hypothesis 3(H3): compared to paternalistic leadership, reduces deviant behavior effectively.

\section{Research Method}

\subsection{Scale selection}

Our questionnaires consist of four scales and personal information. Paternalistic Leadership is assessed a 15-item measure developed by Cheng (2000) [1]. Job satisfaction is assessed by 20-item measure of Minnesota Satisfaction Questionnaire developed by Weiss (1967) [7]. OCB is assessed a 13-item measure developed by Farh (1997) [8]. Deviant behavior is assessed a 15-item measure developed by Zhang Yan (2010) [9]. Questionnaire is used Likert 6 to avoid the doctrine of the mean thought of Chinese (1=strongly disagree and 6=strongly agree).

\subsection{Study objective}

Convenient sampling method has been adapted to survey manager and employees from MBA trainee and corporate training member. Altogether 357 questionnaires have been distributed and 10 invalid questionnaires excluded. Finally, 321 valid questionnaires have been collected. The rate of

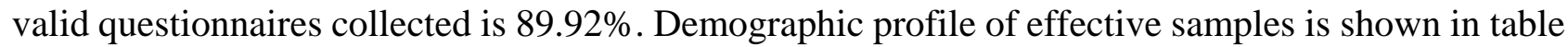
1 
Table 1 Demographic statistical profile of valid samples

\begin{tabular}{|c|c|c|c|}
\hline variable name & frequency(\%) & variable name & frequency(\%) \\
\hline gender & & Age & 12.7 \\
\hline male & 47.3 & Under 25year & 55.9 \\
\hline & & $25-35$ year & 22.9 \\
\hline female & 47.0 & $36-45$ year & 3.5 \\
\hline & & Above 45 year & \\
\hline Work experience & & Education & 3.5 \\
\hline Under 1 year & 10.2 & Under college & 50.8 \\
\hline 1-3 year & 30.2 & college & 33.0 \\
\hline 3-5year & 26.0 & Undergraduate & \\
\hline Above5 year & 30.5 & & 49.5 \\
\hline job position & & enterprise nature & 21.6 \\
\hline General staff & 14 & state-owned & 9.2 \\
\hline primary professional or manager & 33.7 & Private & 17.5 \\
\hline Middle professional or manager & 36.2 & Foreign-funded & else \\
\hline Senior professional or manager & 13.7 & \multicolumn{2}{c}{} \\
\hline
\end{tabular}

\subsection{Reliability analysis}

The author adopt Cronbach $\alpha$ coefficient to test internal consistency reliability of questionnaires through SPSS 17.0. The range of Cronbach a coefficients of subscales is from 0.723 to 0.930 , which are higher than habitual 0.70 standards, indicating good reliability of scales (see table 3).

\section{Data Analysis and Study Result}

\subsection{Confirmatory factor analysis}

The author adopts confirmatory factor analysis to test construct validity of five scales through LISREL8.70. The author uses the following goodness of fit indices: (1) $\mathrm{x} 2 / \mathrm{df}: \chi 2 / \mathrm{d} f<3$, indicating the model fit very well, $3<\chi 2 / \mathrm{d} f<5$, indicating the model can be accepted, $\chi 2 / \mathrm{d} f>5$, indicating the model fit is poor. (2) RMSEA: RMSEA $\leqq 0.1$ indicating the model can be accepted, RM SEA $>0.1$ indicating the model fit is poor. (3) NNFI and CFI: the closer values of NNFI and CFI are to 1, the better model fit. (4) SRMR, the smaller the value of SRMR, the better model fit. SRMR $\leqq 0.05$, indicating the model fit very well, SRMR $>0.05$, indicating the model fit is poor (see table2).

Table 2 the result of confirmatory factor analysis

\begin{tabular}{|c|c|c|c|c|c|c|c|}
\hline & $\chi^{2}$ & $\mathrm{~d} f$ & $\chi 2 / \mathrm{d} f$ & RMSEA & NNFI & CFI & SRMR \\
\hline paternalistic leadership & 221.96 & 87 & 2.55 & 0.071 & 0.96 & 0.97 & 0.053 \\
\hline job satisfaction & 712.35 & 167 & 4.26 & 0.10 & 0.90 & 0.91 & 0.075 \\
\hline OCB & 280.74 & 62 & 4.53 & 0.11 & 0.94 & 0.95 & 0.066 \\
\hline deviant behavior & 300.96 & 87 & 3.46 & 0.089 & 0.97 & 0.97 & 0.050 \\
\hline
\end{tabular}

\subsection{Correlation analysis}

The author adopts Pearson correction analysis to calculate the correlation coefficient of variables (see table3).

The table 3 shows that paternalistic leadership's authority dimension is negatively correlated to work satisfaction and OCB, while positively corrected to deviant behavior. Its dimensions of benevolence and moral integrity are positively correlated to work satisfaction and OCB and negatively to deviant behavior.

In addition, the scale of the Cronbach a is between $0.723 \sim 0.930$, which is higher than the commonly used 0.7 standard, shows that the questionnaire has good reliability. 
Table 3 Mean, standard deviation and correction

\begin{tabular}{|c|c|c|c|c|c|c|c|c|c|c|}
\hline Variable name & $\mathrm{M}$ & $\mathrm{SD}$ & 1 & 2 & 3 & 4 & 5 & 6 & 7 & 8 \\
\hline 2.benevolence & 3.319 & 1.194 & $.645^{* *}$ & $(.845)$ & & & & & & \\
\hline 3.Moral & 3.608 & 1.189 & $.710^{* *}$ & $.552^{* *}$ & $(.825)$ & & & & & \\
\hline 4.Authority & 3.703 & .935 & $\begin{array}{c}-.333^{*} \\
{ }^{*}\end{array}$ & $\begin{array}{c}-.267^{*} \\
{ }^{*}\end{array}$ & $-.309^{* *}$ & $\begin{array}{c}(.758 \\
)\end{array}$ & & & & \\
\hline $\begin{array}{c}\text { 5.Paternalistic } \\
\text { leadership }\end{array}$ & 3.555 & .664 & $.654^{* *}$ & $.796^{* *}$ & $.778^{* *}$ & $.131^{*}$ & $\begin{array}{c}(.723 \\
)\end{array}$ & & & \\
\hline $\begin{array}{c}\text { 6.Job satisfaction } \\
\text { 7.OCB }\end{array}$ & 4.107 & .684 & $.554^{* *}$ & $.383^{* *}$ & $.446^{* *}$ & $\begin{array}{c}-.140 \\
*\end{array}$ & $\begin{array}{c}.440^{*} \\
*\end{array}$ & $(.887)$ & & \\
\hline $\begin{array}{c}\text { 8.Deviant } \\
\text { behavior }\end{array}$ & 2.492 & .779 & $.479^{* *}$ & $.349^{* *}$ & $.391^{* *}$ & $\underset{*}{-.145}$ & $.377^{*}$ & $.566^{* *}$ & $(.905)$ & \\
\hline
\end{tabular}

(note: ${ }^{*} \mathrm{p}<0.05,{ }^{* *} \mathrm{p}<0.01, \mathrm{~N}=321$, Cronbach' $\mathrm{s} \alpha$ in bracket of the diagonal)

\subsection{Impact of paternalistic leadership on work attitude and behavior of employees}

The impact of paternalistic leadership on work attitude and behavior of employees is presented in the figure 1 . The results show that paternalistic leadership has a significantly positive impact on work satisfaction $(\beta=0.78, \mathrm{P}<0.001)$, also has a significantly positive impact on $\mathrm{OCB}(\beta=0.77, \mathrm{P}<0.001)$, meanwhile has a significantly negative impact on deviant behaviour $(\beta=-0.41, \mathrm{P}<0.001)$. The model fit values respectively are $\chi 2 / \mathrm{d} f=3.28, \mathrm{RMSEA}=0.091, \mathrm{NNFI}=0.95, \mathrm{CFI}=0.96, \mathrm{SRMR}=0.063$, indicating model fit is good.

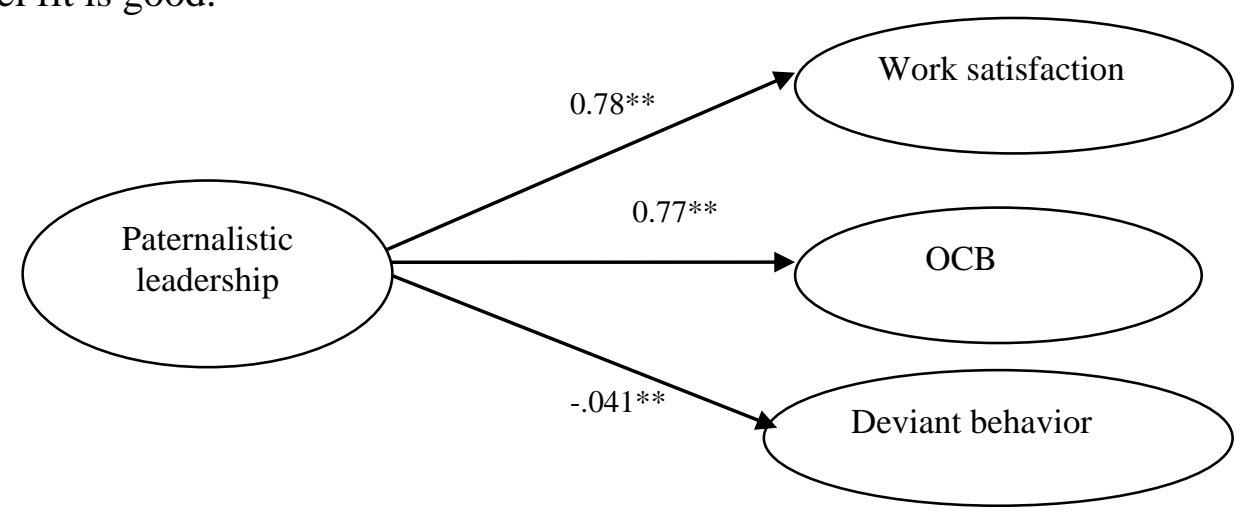

Figure 1 The impact of paternalistic leadership on work attitude and behavior

\section{Conclusion and Advice}

This study has found out that paternalistic leadership is negatively correlated to satisfaction and OCB, while positively correlated to deviant behavior. As for the paternalistic leadership theory which is from Taiwan, It can not to be accepted overall or blindly deny for management theory and practice circle of the Mainland. For many Taiwan enterprises coming to invest in Mainland, It also should adjust the habitual leadership style and corporate culture for a long time, not to simply copying the effective paternalistic leadership and culture in Taiwan to the Mainland and apply to the Mainland's employees. Foxconn is a typical case, from the published literature and research reports, its management style and culture are classic paternalism, which resulted more dissatisfied and behavior deviation, this lesson is worth the entrepreneurs and the theoretical workers' ponder.

\section{Acknowledgments}

This work was supported by the National Natural Science Foundation of China (71962003). 


\section{References}

[1] Cheng Bor-Shiuan, Chou, L. F., \& Farh, J. L. A Triad Model of Paternalistic Leadership: Constructs and Measurement [J]. Indigenous Psychological Research in Chinese Societies, 2000, (14): 3-64.

[2] Cheng Bor-Shiuan, Chou Li-Fang, Min-Ping Huang, Jiing-Lih Farh \& Si-Qing Peng. A Triad Model of Paternalistic Leadership: Evidence from Business Organizations in Mainland China [J]. Indigenous Psychological Research in Chinese Societies, 2003 (14):24-64.

[3] Cheng Bor-Shiuan, Chou Li-Fang, Wu Tsung-Yu, Huang Min-Ping, Farh Jiing-Lih. Paternalistic Leadership and Subordinate Responses: Establishing a Leadership Model in Chinese Organizations [J] Asian Journal of Social Psychology, 2004, 7 (1): 89-117.

[4] Farh J.L., Earley R.C., \& Lin S.C. Impetus for Action: A Cultural Analysis of Justice and Organizational Citizenship Behavior in Chinese Society [J]. Administrative Science Quarterly, 1997, (3),41-59.

[5] Hepworth, W., \& Towler, A., The Effects of Individual Differences and Leadership on Workplace Aggression [J]. Journal of Occupational Health Psychology, 2004, (9).52-64.

[6] Tepper B.J., M.K. Duffy, J.D. Shaw, Personality Moderators of the Relationship between Abusive Supervision and Subordinate's Resistance [J]. Journal of Applied Psychology, 2001, (86), 974-983.

[7] Weiss, M. J., Dawis, R. V., England, G. W., \& Lofquist, L. H. Manual for the Minnesota Satisfaction Questionnaire[M]. Minneapolis: University of Minnesota, 1967.

[8] Farh, Larry J L; Cheng, B S. Paternalistic leadership in Chinese organizations: A cultural analysis [J] Indigenous Psychological Research in Chinese Societies, 2000, 13: 127-180.

[9] Zhang Yan. The Research on the Relationship of Human Resource Practices and Workplace Deviant Behavior[D], Sichuan University doctoral thesis, 2010 (in Chinese). 